\title{
Growth Factor-Reinforced ECM Fabricated from Chemically Hypoxic MSC Sheet with Improved In Vivo Wound Repair Activity
}

\author{
Hui-Cong Du, ${ }^{1}$ Lin Jiang, ${ }^{1}$ Wen-Xin Geng, ${ }^{1}$ Jing Li, ${ }^{2}$ Rui Zhang, ${ }^{1}$ Jin-Ge Dang, \\ Mao-Guo Shu, ${ }^{3}$ and $\mathrm{Li}-\mathrm{Wen} \mathrm{Li}^{1}$ \\ ${ }^{1}$ Key Laboratory of Resource Biology and Biotechnology in Western China, Northwest University, Ministry of Education, \\ Xian, Shaanxi 710069, China \\ ${ }^{2}$ Department of Plastic and Burn Surgery, Tangdu Hospital, Forth Military Medical University, Xi'an, Shaanxi 710038, China \\ ${ }^{3}$ Department of Plastic Surgery, The First Affiliated Hospital of Xian Jiaotong University, Xian, Shaanxi 710061, China
}

Correspondence should be addressed to Mao-Guo Shu; shumaoguo@163.com and Li-Wen Li; liven@nwu.edu.cn

Received 11 May 2017; Accepted 1 August 2017; Published 5 September 2017

Academic Editor: Martin Bornhäuser

Copyright (c) 2017 Hui-Cong Du et al. This is an open access article distributed under the Creative Commons Attribution License, which permits unrestricted use, distribution, and reproduction in any medium, provided the original work is properly cited.

\begin{abstract}
MSC treatment can promote cutaneous wound repair through multiple mechanisms, and paracrine mediators secreted by MSC are responsible for most of its therapeutic benefits. Recently, MSC sheet composed of live MSCs and their secreted ECMs was reported to promote wound healing; however, whether its ECM alone could accelerate wound closure remained unknown. In this study, $\mathrm{Nc}$-ECM and Cc-ECM were prepared from nonconditioned and $\mathrm{CoCl}_{2}$-conditioned MSC sheets, respectively, and their wound healing properties were evaluated in a mouse model of full-thickness skin defect. Our results showed that Nc-ECM can significantly promote wound repair through early adipocyte recruitment, rapid reepithelialization, enhanced granulation tissue growth, and augmented angiogenesis. Moreover, conditioning of MSC sheet with $\mathrm{CoCl}_{2}$ dramatically enriched its ECM with collagen I, collagen III, TGF- $\beta 1$, VEGF, and bFGF via activation of HIF- $1 \alpha$ and hence remarkably improved its ECM's in vivo wound healing potency. All the Cc-ECM-treated wounds completely healed on day 7, while Nc-ECM-treated wounds healed about $85.0 \% \pm 8.6 \%$, and notreatment wounds only healed $69.8 \% \pm 9.6 \%(p<0.05)$. Therefore, we believe that such growth factor-reinforced ECM fabricated from chemically hypoxic MSC sheet has the potential for clinical translation and will lead to a MSC-derived, cost-effective, bankable biomaterial for wound management.
\end{abstract}

\section{Introduction}

Wound healing is one of the most complex and dynamic biological processes that occurs in human lifespan $[1,2]$. Improper or impaired wound healing not only leads to significant morbidity and mortality but also places immense burden on healthcare systems worldwide. Because of the great importance and demand for wound management products, skin substitute biomaterials have attracted more and more intensions in recent years. And a large variety of biomaterials capable of promoting wound healing have been derived from allogeneic or xenogeneic resources, chemical or recombinant materials, or a combination of both $[3,4]$. Among these materials, natural resource-derived extracellular matrices
(ECMs) are of special interest since such ECMs can provide structural support and scaffolding as well as biochemical signals for tissues and cells simultaneously [5]. Acellular dermal matrix $(\mathrm{ADM})$, the natural ECM fabricated from decellularized dermal tissue, has long been used to replace lost skin tissues in clinical settings [6, 7]. However, ADM contains only low doses of native growth factors which can hardly be increased due to ethical concerns [8]. Therefore, natural or artificial ECM alternatives enriched in growth factors are worthwhile pursuing [5].

Cell sheet technology is a novel strategy to fabricate scaffold-free 3D tissues and shows extraordinary potency in tissue engineering and regenerative medicine $[9,10]$. Recently, cell sheets derived from mesenchymal stem cells 
(MSCs) isolated from adipose tissue were reported to accelerate cutaneous wound healing by promoting reepithelialization and revascularization [11-13]. However, their translating from bench-top to clinic is limited by some drawbacks, such as the risk of aberrant immune responses and cost implications for maintaining cell viability in stringent storage and transport conditions. Accumulating evidences demonstrated that MSCs participate in tissue repair and regeneration mainly through their secretome instead of direct differentiation into local cell types as once thought [14, 15]. Among MSC's secretome, ECM is mainly composed of collagens and acts as a reservoir for growth factors which can be rapidly mobilized to stimulate wound repair $[16,17]$. Therefore, ECM seems to be a better choice in comparison to its original cell sheet because it is cost-effective, readily available, and devoid of cellular antigens. Moreover, it might be feasible to manipulate the reservoir of growth factors trapped in the ECM and hence its wound healing potency.

Hypoxia-inducible factor-1 (HIF-1) is a well-known transcription factor that mediates the cellular adaptive responses to hypoxia and plays critical roles in the process of wound repair $[18,19]$. It not only regulates the expression of several ECM-bound growth factors, including VEGF, bFGF, and TGF- $\beta 1$ [20], but also participates in regulation of collagen deposition, fiber alignment, and ECM stiffening [21]. In addition to low oxygen tension exposure, cobalt chloride $\left(\mathrm{CoCl}_{2}\right)$, the widely used chemical hypoxia inducer, is well documented to activate HIF-1 by increasing the stability of its oxygen labile $\alpha$ subunit [22]. Therefore, we proposed that $\mathrm{CoCl}_{2}$ conditioning of MSC sheet could enrich its ECM with growth factors via a HIF- $1 \alpha$-dependent pathway and thereby improved its wound healing properties.

In this study, the effects of $\mathrm{CoCl}_{2}$ conditioning on the expression of collagens and growth factors in MSC sheets and their derived ECMs were investigated. And the in vivo wound healing efficacy of the enriched ECMs derived from chemically hypoxic MSC sheets was evaluated in a mouse model of full-thickness skin defect.

\section{Materials and Methods}

2.1. Isolation of MSCs. Two-week-old New Zealand rabbits $(n=4)$ were obtained from Animal Center of Fourth Military Medical University. Rabbit bone marrow MSCs were isolated in accordance with IACUC approval of Northwest University and cultured as reported previously with minor modifications [23]. MSCs were cultured in DMEM/F12 medium (Corning, USA) with $10 \%$ fetal bovine serum (MP Biomedicals, USA), with $0.272 \mathrm{~g} / \mathrm{L}$ L-glutamine (Sigma, USA), $100 \mu \mathrm{g} / \mathrm{mL}$ penicillin and $100 \mu \mathrm{g} / \mathrm{mL}$ streptomycin at $37^{\circ} \mathrm{C}$, and $5 \% \mathrm{CO}_{2}$. Cells at passage 2 were used for all experiments.

\subsection{Formation of Cell Sheets and Chemical Hypoxia Condi-} tioning. Primary MSCs were seeded at 20,000 cells per $\mathrm{cm}^{2}$ in complete medium supplemented with $100 \mu \mathrm{g} / \mathrm{mL}$ vitamin $\mathrm{C}$ (Sigma, USA). Half of the medium was changed daily. Seven days later, chemical hypoxia conditioning was performed by adding $\mathrm{CoCl}_{2}$ to the culture medium to final concentration of $100 \mu \mathrm{M}$. After another 7-day culture, cell sheets were intactly harvested from the Petri dishes and their derived ECMs were achieved by a standard decellularization procedure [24].

2.3. Fabrication of ECMs from Cell Sheets. Decellularization was conducted in warm double distilled water supplemented with $20 \mathrm{mM}$ ammonium hydroxide (Sigma, USA) for $10 \mathrm{~min}$ with shaking on a rotary shaker. After being washed with cold PBS for three times, the resulting cell-free ECMs were treated with DNase I (Sigma, USA) for $30 \mathrm{~min}$ at $37^{\circ} \mathrm{C}$ to eliminate DNA residues. Then DNA-free ECMs were washed with PBS for five times and stored at $-20^{\circ} \mathrm{C}$ for 4 weeks before use.

2.4. Western Blot Analysis. All the MSC sheets and their derived ECMs were cut into pieces and then were ground in a glass homogenizer on ice in cold RIPA buffer (with phenylmethylsulfonyl fluoride). After centrifugation for $15 \mathrm{~min}$ at $4^{\circ} \mathrm{C}, 14,000 \times \mathrm{g}$, the supernatants were transferred to new tubes. Protein concentrations were evaluated by BCA protein assay kit (TaKaRa, Japan). Equal amounts of total protein of different samples were loaded for western blot analysis using standard procedures. HIF- $1 \alpha$ antibody, collagen I $\alpha 1$ antibody, and collagen III $\alpha 1$ antibody were purchased from NOVUS Biologicals (USA), TGF- $\beta 1$ antibody was purchased from Abcam (USA), and VEGF antibody, bFGF antibody, $\beta$ actin antibody, mouse anti-rabbit IgG-HRP, and goat antimouse IgG-HRP were purchased from Santa Cruz Biotech (USA). The protein levels were normalized by using $\beta$-actin as an internal control.

2.5. Mouse Models of Full-Thickness Skin Defect Wounds. Female Balb/C mice (8 10 weeks old, $n=48$ ) were obtained from Animal Center of Fourth Military Medical University. All in vivo experiments were approved by IACUC of Northwest University. The mice were randomly divided into 3 groups: the control group received no treatment and experimental groups were treated with ECMs fabricated from nonconditioned MSC sheets (Nc-ECMs) or ECMs from $\mathrm{CoCl}_{2}$-conditioned MSC sheets (Cc-ECMs). The in vivo wound healing experiment was conducted in a mouse model of full-thickness skin defect [25]. Briefly, two $6 \mathrm{~mm}$ diameter full-thickness wounds were created on the back of each mouse. Silicone rubber ring with inner diameter of $6 \mathrm{~mm}$ was adhered to the skin around the wound to prevent wound from shrinkage and to ensure wound healed through granulation tissue formation and reepithelialization, a process similar to that occurring in humans [25]. And ECMs of 7-mm diameter were transplanted onto the wound beds immediately after wounding. Then all the wounds were covered with Vaseline gauze to prevent ECM from drying and dressed with selfadhering elastic bandages. The photographs of the wounds were taken on days $0,3,5$, and 7 using Canon Digital Camera (EOS 700D with Macro Lens EF-S 60 mm f/2.8 USM, Canon, Inc., Tokyo, Japan) and analyzed for healing progress using Image J software.

2.6. Histological Analysis. All samples were fixed overnight in $4 \%$ paraformaldehyde at $4^{\circ} \mathrm{C}$. After alcoholic dehydration and paraffin embedded, the samples were sectioned at $5 \mu \mathrm{m}$ using a Leica RM2235 rotary microtome. Hematoxylin and 


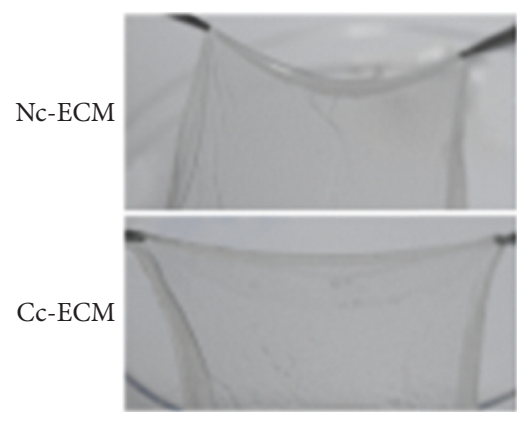

(a)

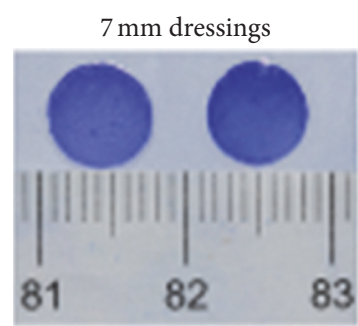

(b)

FIGURE 1: Morphology of MSC sheets derived ECMs. Representative macroscopic images of Nc-ECMs and Cc-ECMs (a). The 7 mm diameter ECM dressings were stained with coomassie blue dye for 5 minutes (b).

eosin (H\&E) staining, Masson's trichrome (MTC) staining, and picrosirius red (PSR) staining were performed and the sections were observed under a Leica DMI $6000 \mathrm{~B}$ automated fluorescence microscope or a Leica M205 FA stereomicroscope.

2.7. Statistical Analysis. All data were given as mean \pm s.d. Statistical evaluation was performed using one-way analysis of variance (ANOVA), followed by Dunnett's $t$-test for experimental groups and control group comparisons and Bonferroni's test for experimental groups comparison. The results of western blot were analyzed by independent-sample $T$ test.

\section{Results}

3.1. Characteristics of MSC Sheets and Their Derived ECMs. All the acellular ECMs were semitransparent and no macroscopic differences were identified between different groups. The ECMs could be easily handled with forceps and cut into round shape, indicating that they were mechanically stable enough for in vitro manipulation (Figure 1). PSR staining showed that all cell sheets were composed of 23 layers of MSCs embedded in large amounts of ECMs (Figure 2(a)). The red-stained collagens observed in brightfield microscopy and the green-stained collagen III in polarization microscopy were more significant in both $\mathrm{CoCl}_{2}$ conditioned MSC sheet and its derived Cc-ECM than those in nonconditioned controls (Figures 2(b) and 2(d)). Moreover, decellularization removed most of MSCs and resulted in ECMs with highly porous microstructures (Figure 2(c)).

3.2. $\mathrm{CoCl}_{2}$ Activates HIF-1 $\alpha$ in MSC Sheets. HIF- $1 \alpha$ is subject to continuous proteasomal degradation under normoxic conditions and its protein level elevates quickly in response to hypoxic stress. In addition to culture cells under hypoxia conditions, $\mathrm{CoCl}_{2}$ has been widely used to induce chemical hypoxia in many other cell types [26-30]. In this study, $\mathrm{CoCl}_{2}$ exposure significantly increased the protein level of HIF-1 $\alpha$ in MSC sheets (Figure 3(a)), and a 13.5-fold increase was detected in our study, indicating that chemical hypoxia was successfully induced in MSC sheets (Figure 4(a)).
3.3. $\mathrm{CoCl}_{2}$ Enriches Collagens and Growth Factors in ECMs. Many collagen-based biomaterials have been developed as wound biodressings and showed positive outcomes in preclinical and clinical wound management [31]. And collagen I and collagen III are known to be involved in the process of wound healing [32]. We showed that $\mathrm{CoCl}_{2}$ conditioning induced a 5.6-fold increase in collagen I expression and a 1.9fold increase in collagen III relative to the nonconditioned MSC sheet (Figures 3(a) and 4(a)). And after decellularization, the retained amounts of collagen I and collagen III in Cc-ECM were approximately 6.1-fold and 3.0-fold of that in Nc-ECM, respectively (Figures 3(b) and 4(b)). These results indicated that $\mathrm{CoCl}_{2}$ not only upregulated the expression of collagen I and collagen III in MSC sheets but also enhanced their preservation in the resulting acellular ECMs.

Since TGF- $\beta 1$ plays important roles in reepithelialization as well as collagen deposition through regulating fibroblast and myofibroblast activities [16, 33], we also assessed the effect of chemical hypoxia conditioning on its expression. The results demonstrated that $\mathrm{CoCl}_{2}$ induced a 3.4-fold increase in TGF- $\beta 1$ level in MSC sheet (Figures 3(a) and 4(a)). However, most TGF- $\beta 1$ was lost during decellularization and trace amount of TGF- $\beta 1$ was detected only in the Cc-ECM (Figures 3(b) and 4(b)).

VEGF and bFGF are the two well-known growth factors secreted by multiple types of cells and function as biochemical cues for wound repair $[34,35]$. Both VEGF and bFGF levels were significantly elevated by $\mathrm{CoCl}_{2}$ (Figure 3(a)), and $\mathrm{CoCl}_{2}$ induced a 2.5-fold increase in VEGF and a 1.6-fold increase in bFGF relative to the nonconditioned MSC sheet which were observed, respectively (Figure 4(a)). The results also revealed that, after decellularization, more amounts of VEGF and bFGF were retained in Cc-ECM than in Nc-ECM (Figures 3(b) and 4(b)).

3.4. Enriched ECM from Chemically Hypoxic MSC Sheet Accelerates Wound Healing. Collectively, all the in vitro data showed that conditioning MSC sheet with $\mathrm{CoCl}_{2}$ enriched its ECM with both collagens and growth factors. Then a mouse model of full-thickness skin defect was employed to evaluate the in vivo wound healing efficacy of the enriched ECM. Although Nc-ECM did promote wound repair, which 


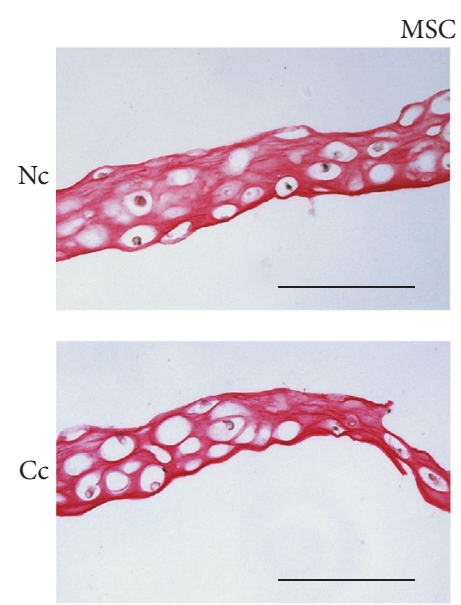

(a)
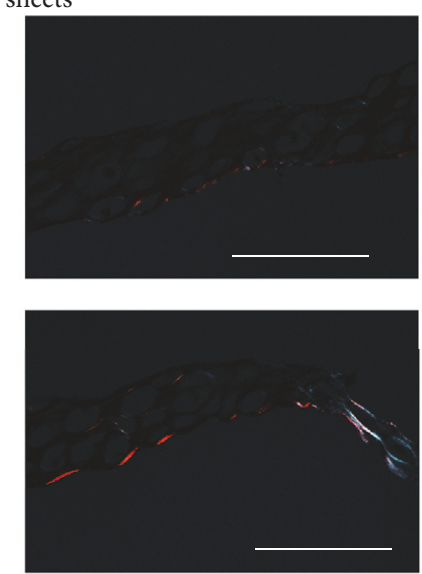

(b)
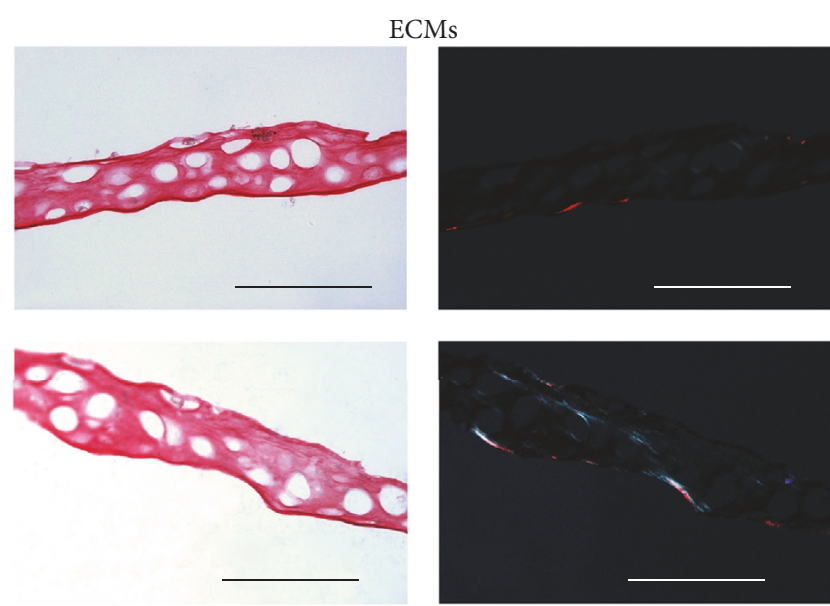

(c)

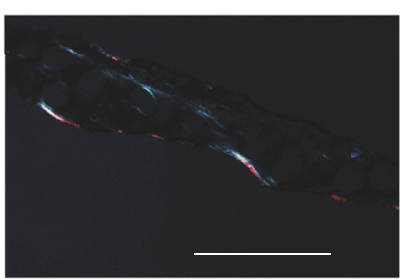

(d)

FIGURE 2: PSR staining of MSC sheets and their derived ECMs. Imaging of MSC sheets and ECMs under light microscopy (a, c). Imaging of birefringent collagen through crossed polarization light microscopy. Large orange-red fibers were collagen I and thin blue-green filamentous fibers were collagen III (b, d). Scale bars represent $100 \mu \mathrm{m}$.

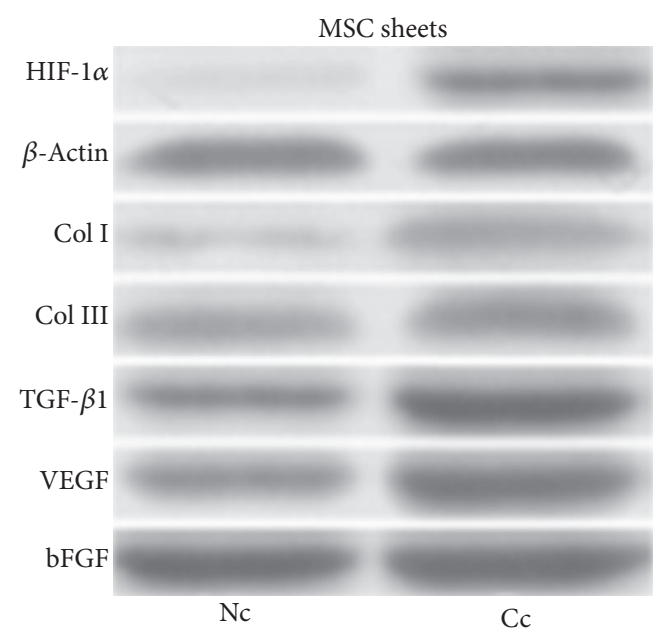

(a)

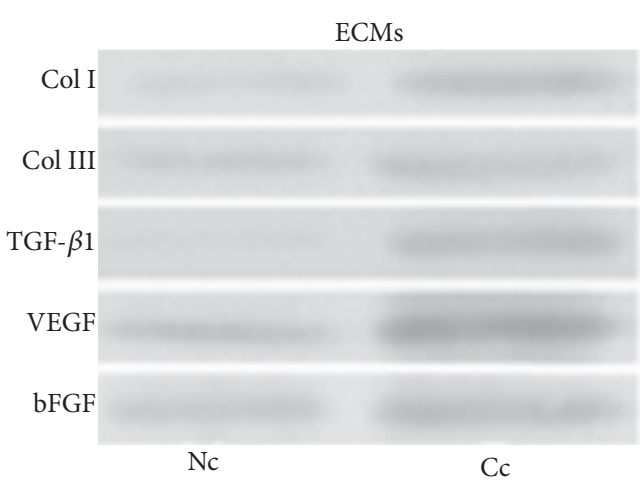

(b)

FIgURE 3: Western blot analysis of HIF- $1 \alpha$, collagens, and growth factors in MSC sheets and their derived ECMs. The proteins expressed in MSC sheets (a). The proteins expressed in their derived ECMs. The equal amounts of total protein in two groups were loaded for western blot analysis (b).

were indicated by the higher healed percentages at all time points in its treated wounds comparing with the nontreatment control (Figures 5 and 6), the wound healing property of Cc-ECM was more robust and most of its treated wounds completely healed at day 7 postoperatively, while $\mathrm{Nc}$ ECM-treated wounds healed about $85.0 \% \pm 8.6 \%$, and notreatment wounds only healed $69.8 \% \pm 9.6 \%(p<0.05)$. Moreover, PSR staining showed that the edges of all ECMtreated wounds contained higher collagen content, and thick collagen bundles leading from the uninjured dermis into the granulation tissue were observed (Figures 7(a) and 7(b)). Furthermore, the Cc-ECM-treated wounds exhibited prominent integration of the granulation tissue into the uninjured adjacent dermis. Collagen within the Cc-ECM-treated wound edge was well-oriented, connecting between the surrounding dermis and the granulation tissue, while less such alignment was observed in the Nc-ECM-treated wound edge (Figure 7(c)).

It is noteworthy that no inflammatory signs or visible indication of necrosis was observed in wound tissues during the experimental period, indicating that ECMs derived from xenogeneic MSC sheets induced little immune responses in immunocompetent mice, which was congruent with the previously reported results [36].

3.5. Enriched ECM Promotes Early Adipocyte Recruitment and Granulation Tissue Formation. The results of histological analysis demonstrated that adipocytes, which showed empty 


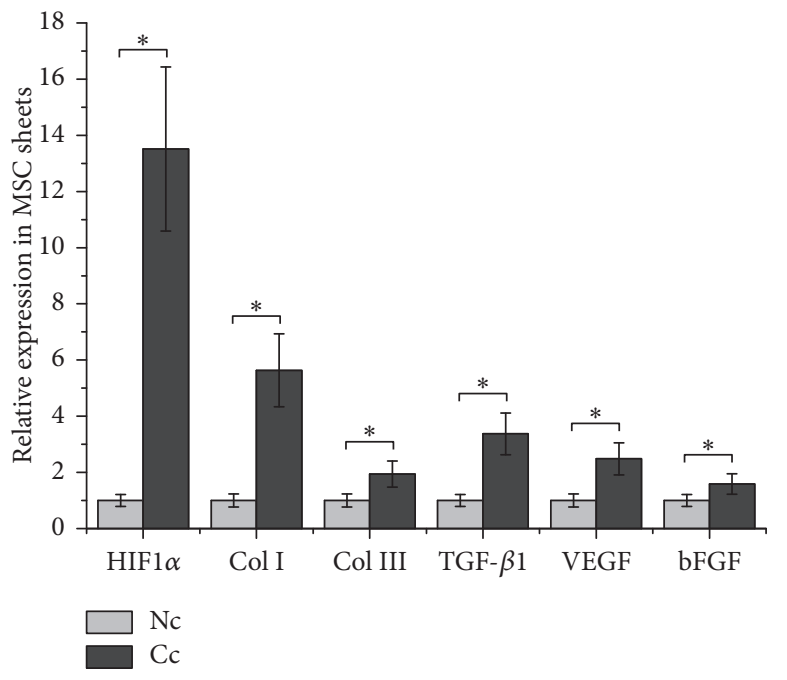

(a)

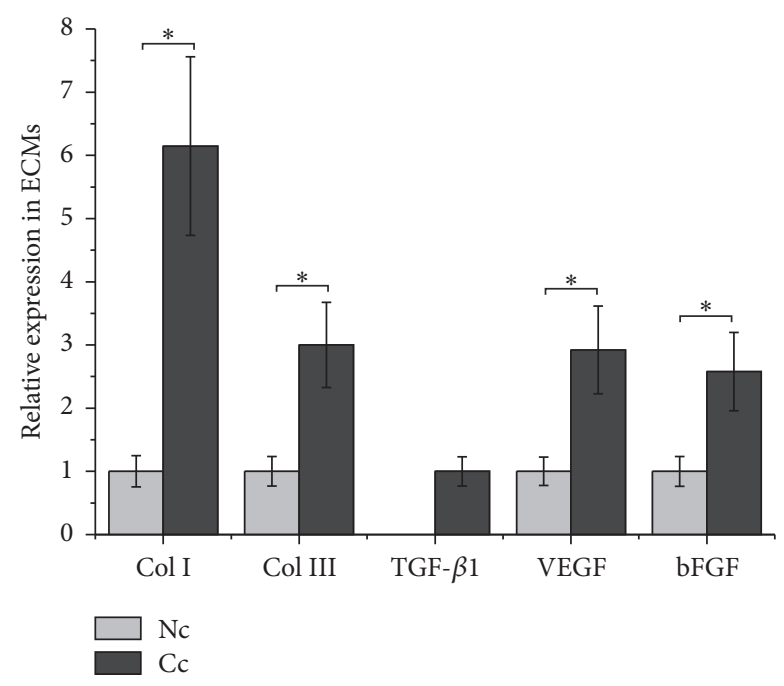

(b)

FIgURE 4: Effects of $\mathrm{CoCl}_{2}$ on protein expression. The relative protein levels of HIF-1 $\alpha$, collagens, and growth factors in MSC sheets (a). The relative protein levels of collagens and growth factors in ECMs (b). ${ }^{*} p<0.001, n=8$.

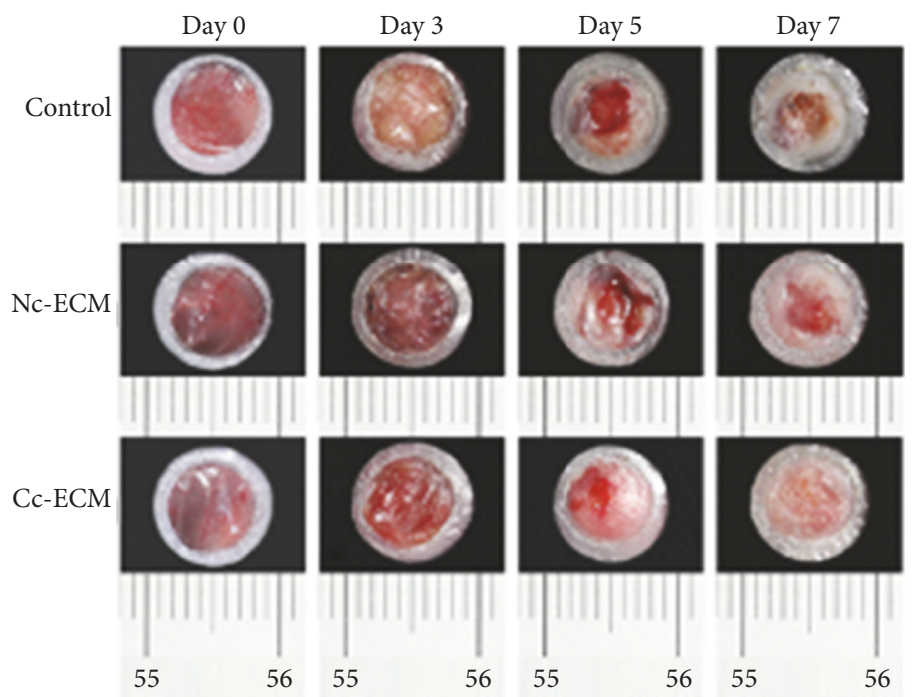

FIGURE 5: ECMs accelerated wound closure in a mouse model of full-thickness skin defect. Representative images of wound closure during a 7-day in vivo wound healing.

cytoplasm in H\&E-stained sections, filled the wound gap thoroughly on day 3 postoperatively in Cc-ECM-treated mice, partly in the Nc-ECM-treated mice, and scarcely in the nontreated mice (Figure 8 ). On day 5, adipocytes fully covered the wound bed in the Nc-ECM-treated as well as the nontreated wounds, whereas in the Cc-ECM-treated mice, adipocytes began to disappear and reepithelialization occurred. On day 7, thick and well-structured granulation tissues were observed only in Cc-ECM-treated mice in contrast to little granulation tissues formed in Nc-ECMtreated and nontreated mice (Figures 8 and 9(a)). Although the underlying mechanisms remain unexplored, it seems that early adipocyte recruitment was associated with improved wound repair.

3.6. Enriched ECM Promotes Reepithelialization and Angiogenesis. When reepithelialization was concerned, we noticed that epidermal cells at the wound edges, which seemed to be originated from adjacent hair follicles, proliferated in all the ECM-treated wounds but not in nontreated wounds at day 3. Moreover, epidermal cells proliferated pronouncedly and began to migrate towards the wound center in CcECM-treated wounds and neoepidermis almost fully covered the wound bed by day 5 (Figure 8), indicating an enhanced 


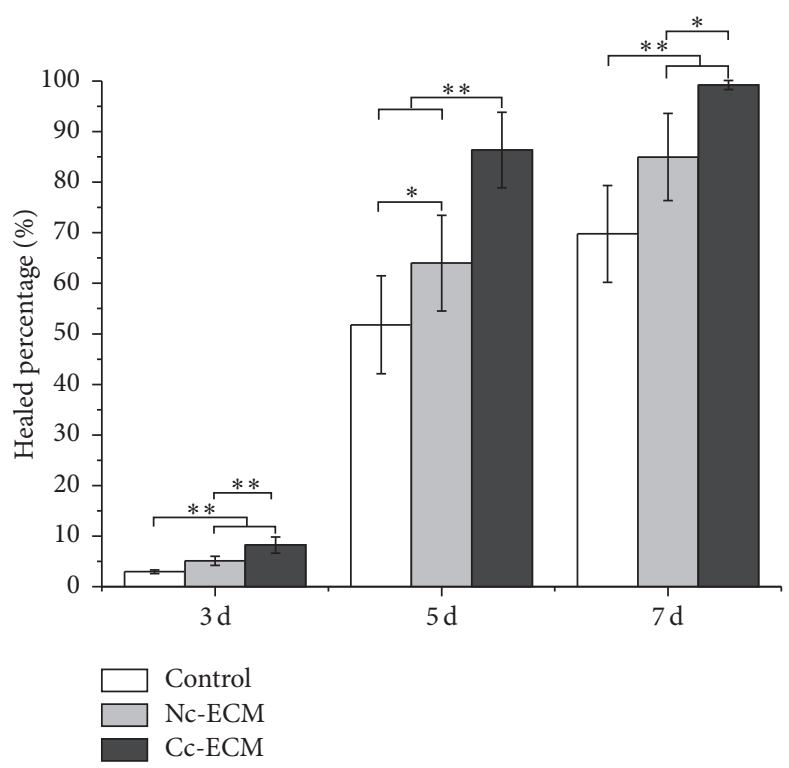

FIGURE 6: Quantitative analysis of wound closure. Wound closure over time was presented as percentage of healed wound area relative to initial wound area. ${ }^{*} p<0.05 ;{ }^{* *} p<0.001 ; n=8$.

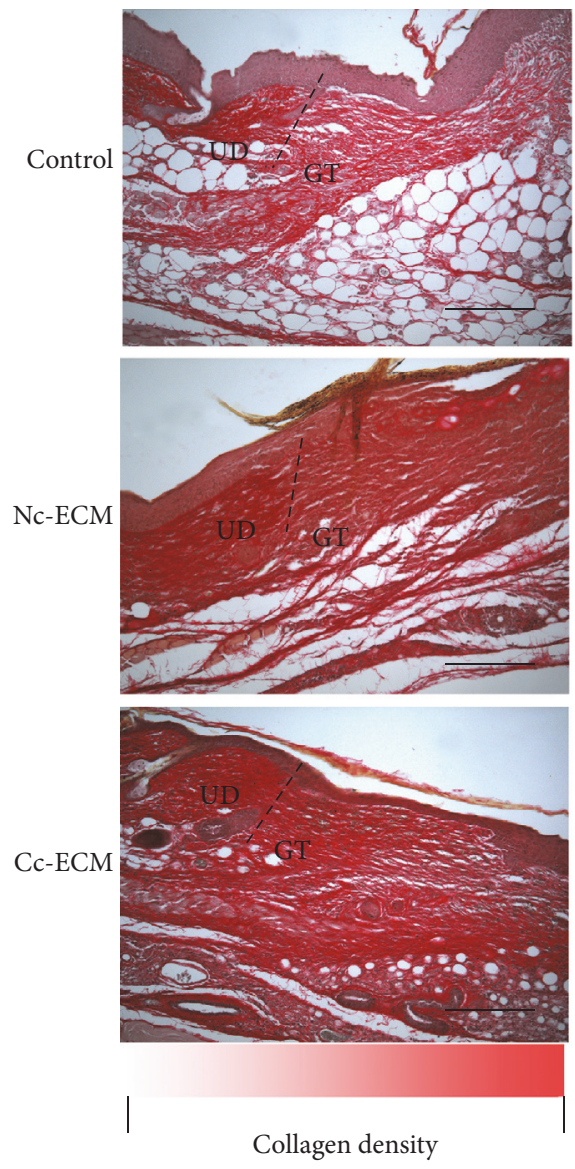

(a)
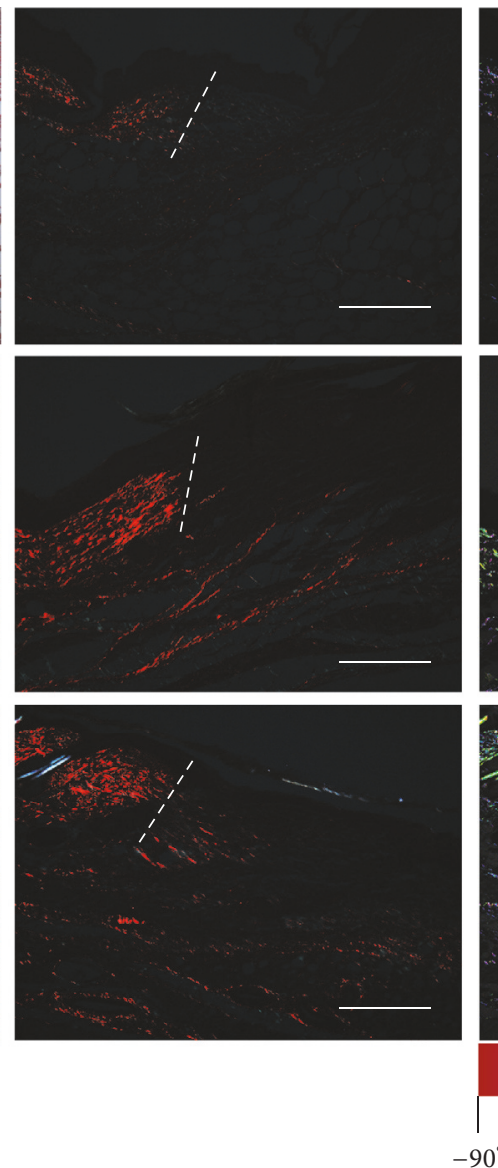

(b)
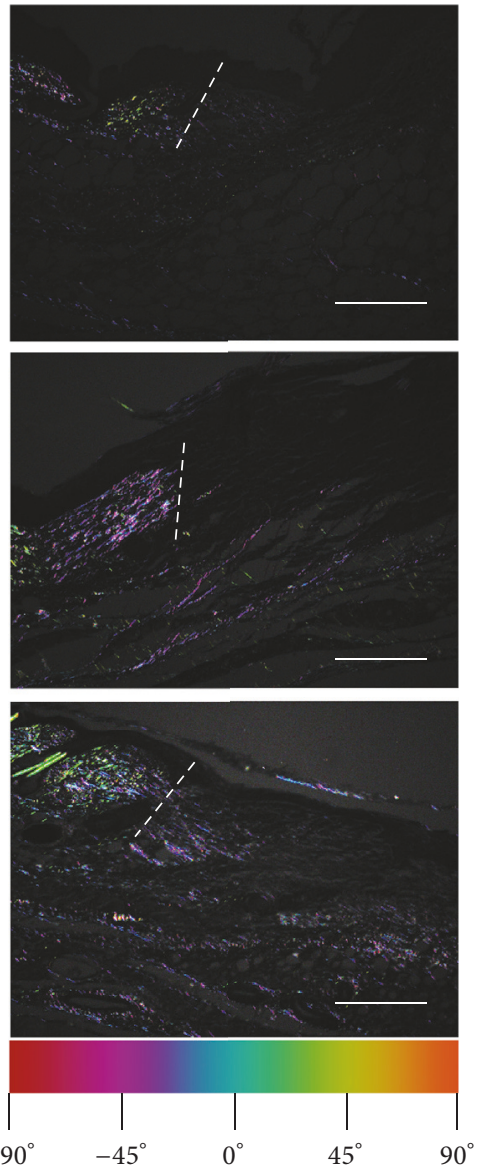

(c)

FIGURE 7: Tissue infiltration and wound edge integration were enhanced with ECMs at day 7 postoperatively. PSR staining of wound edge ( $\mathrm{UD}=$ uninjured dermis, GT = granulation tissue) (a). Imaging of birefringent collagen through crossed polarization light microscopy. Large orange-red fibers were collagen I and thin blue-green filamentous fibers were collagen III (b). Color maps of fiber orientations were performed using Orientation J software (c). Scale bars represent $200 \mu \mathrm{m}$. 


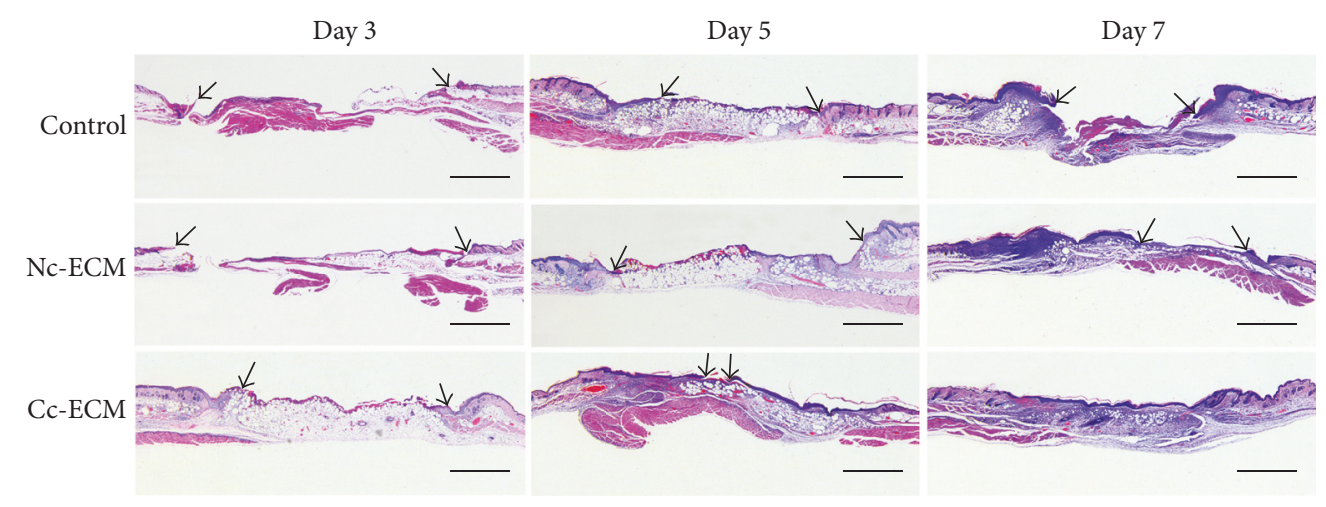

FIGURE 8: Histological analysis of wound healing. Wound sections on 3, 5, and 7 days after operation were stained with H\&E. Black arrows highlighted the epidermal tongue. Scale bars represent $1 \mathrm{~mm}$.

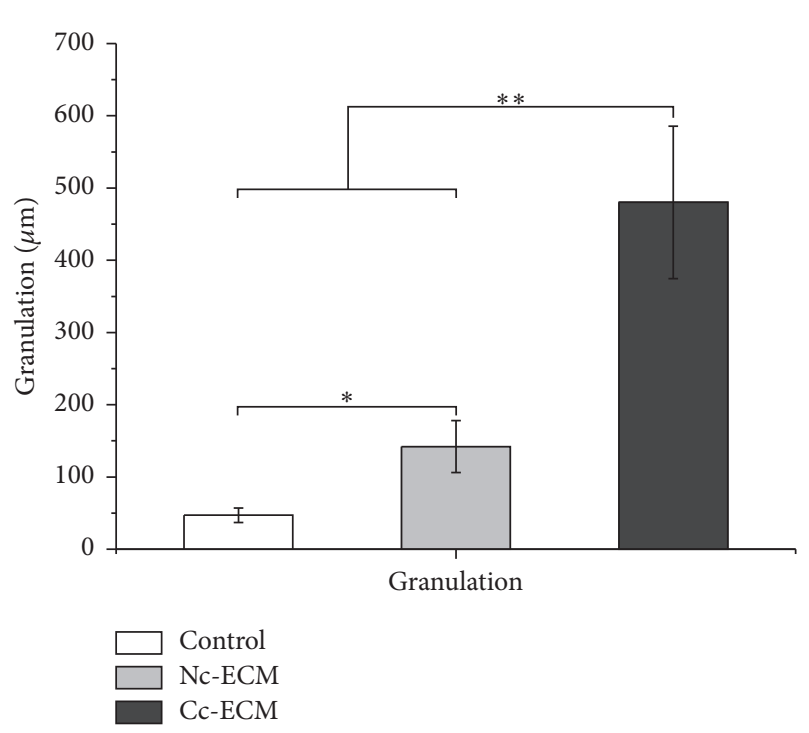

(a)

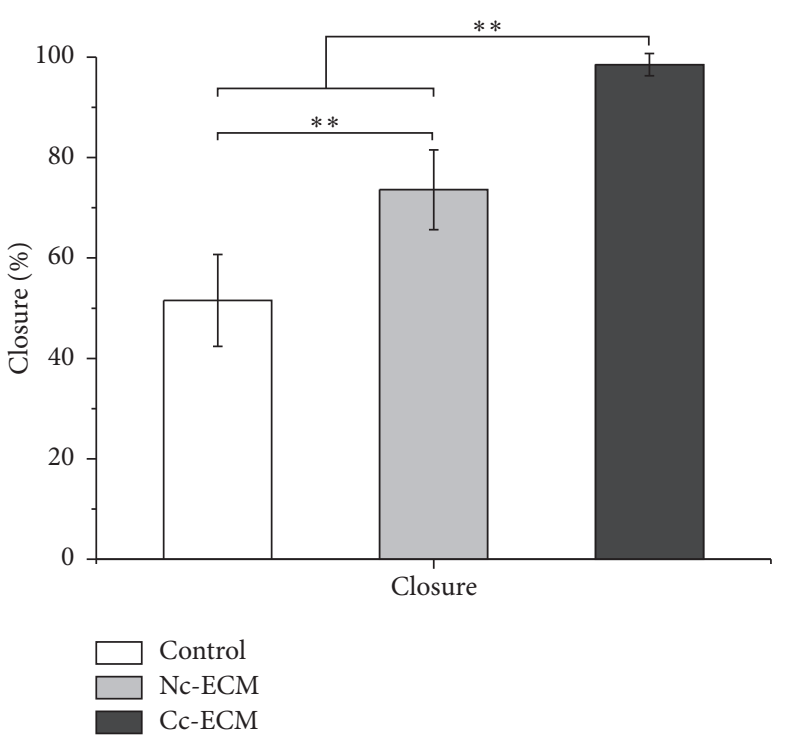

(b)

FIGURE 9: ECMs accelerated granulation tissue formation and reepithelialization. Granulation tissue thickness of the center of wounds at day 7 postoperatively (a). Percentage of closure of the epidermal gap was evaluated at day 7 postoperatively (b). ${ }^{*} p<0.05{ }^{* *} p<0.001 ; n=8$.

reepithelialization, which was consistent with the in vitro analysis of TGF- $\beta 1$ expression. On day 7, although the bilateral epidermal tongues of Nc-ECM-treated wounds migrated significantly $(73.6 \% \pm 7.9 \%)$ in comparison to that of the nontreated $(51.5 \% \pm 9.2 \%)(p<0.001)$, large epidermis gap still existed (Figure 9(b)). Furthermore, the total number of vessels counted in Cc-ECM-treated wounds was more than two times of that in Nc-ECM-treated (Figures 10(a) and 10(b)), indicating an augmented angiogenesis which seemed to result from the enhanced retention of VEGF and bFGF in Cc-ECM.

\section{Discussion}

The influence of $\mathrm{CoCl}_{2}$-induced chemical hypoxia conditioning of MSC sheets on the wound healing potency of their derived ECMs was investigated and the data revealed that $\mathrm{CoCl}_{2}$ conditioning results in ECMs enriched in both collagens and growth factors via a HIF- $1 \alpha$-dependent pathway, which exhibit an improved therapeutic efficacy in healing full-thickness skin wounds.

Previous reports showed that MSC treatment by means of intradermal MSC injection, implantation of MSC sheet or MSC-loaded biomaterials, mobilization, and recruitment MSC into the wound beds exerts beneficial effects on cutaneous wound healing through multiple mechanisms [37, 38]. Now it is clear that most of the therapeutic benefits of MSC, such as rapid reepithelialization, pronounced granulation tissue growth, and enhanced angiogenesis, are mainly attributed to its paracrine mediators [14, 15]. In the present study, we showed that MSC sheet-derived acellular ECMs contained abundant collagens and growth factors and 


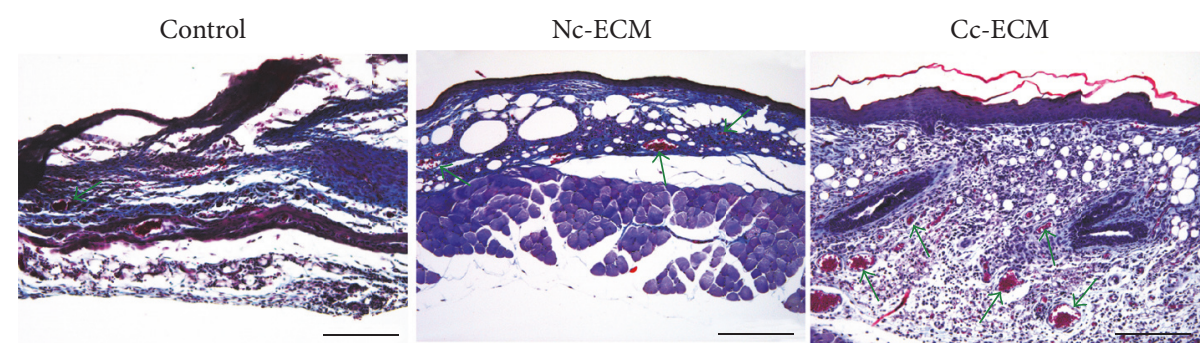

(a)

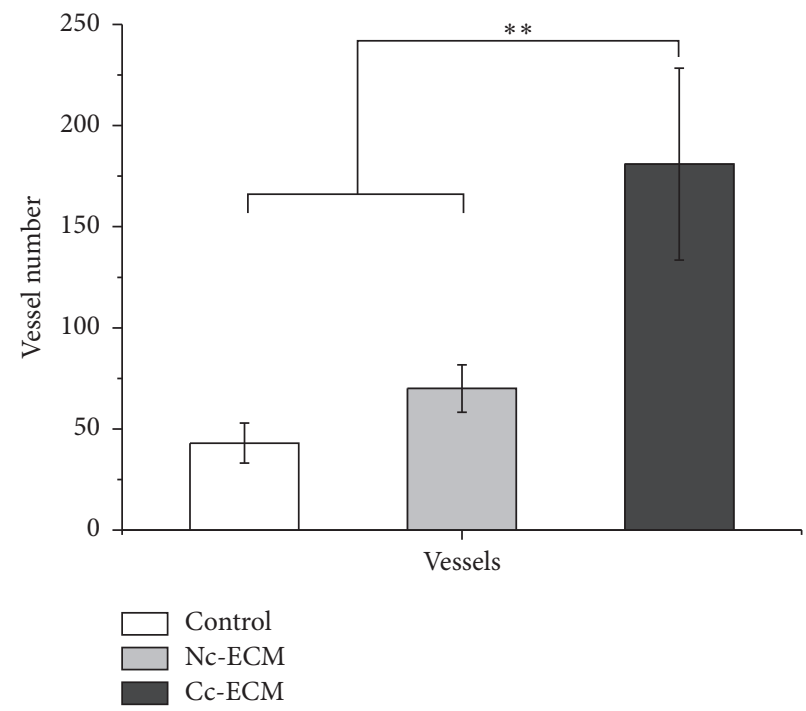

(b)

FIGURE 10: ECMs accelerated angiogenesis. High power field (HPF) (100x) imaging of the center in wound granulation tissues stained with MTC at day 7 postoperatively (a). Scale bars represent $200 \mu \mathrm{m}$. Number of vessels per HPF at day 7 postoperatively (b). ${ }^{* *} p<0.001 ; n=8$.

significantly promoted wound closure in mice models of fullthickness skin defect, indicating that the ECM portion of MSC secretome possesses active wound healing ability.

It has been reported that hypoxia preconditioning can enhance the tissue repair ability of MSCs [39], and activation of HIF- $1 \alpha$ has been considered as an efficient strategy to promote wound repair [21]. Moreover, conditioned medium from hypoxic MSCs can also accelerate wound healing [4042]. So we asked whether exposing MSC sheets to chemical hypoxia could improve the wound healing efficacy of their derived ECMs. Our results showed that $\mathrm{CoCl}_{2}$-induced chemical hypoxia was a simple but efficient strategy to activate HIF- $1 \alpha$-dependent pathway in MSC sheets and enriched their ECMs with collagens and growth factors by upregulation their expression as well as increasing their preservation during decellularization process. Most of all, the enriched ECMs showed extraordinary in vivo wound healing potency.

ECM-based biologic scaffolds are currently used to fabricate functional organs and tissues to repair, restore, replace, or regenerate damaged tissues or organs. And many robust and effective decellularization protocols have been established to remove all cellular components from a large variety of tissues and organs while maximizing the preservation of their native composition and three-dimensional architectures of the remaining ECMs [43]. In this study, instead of the stringent decellularization procedure for fabricating ADMs from thick dermal tissues [44, 45], a mild procedure was selected to decellularize MSC sheets to minimize the loss of bioactive molecules because they are thinner (thinner than $100 \mu \mathrm{m}$ ) than skin tissues from which ADMs are derived (the thickness of the tissues varies from $300 \mu \mathrm{m}$ to $3000 \mu \mathrm{m}$ ) [44-49]. Nonetheless, a dramatic loss of both collagens and growth factors in the resulting ECMs was observed. It has been known that the divalent cross-links in collagen are converted into mature and stable trivalent cross-links and thus results in decreased collagen solubility during tissue maturation $[50,51]$. Since the Cc-ECM and Nc-ECM were prepared from two-week cultures of MSC sheets, we attributed the loss of collagens and the trapped growth factors to the lack of cross-linking in naive collagen freshly synthesized by MSC. Moreover, lysyl oxidases, which are reported to be upregulated by hypoxia stress and play an important role in initiating collagen cross-linking [52], seemed to contribute to the enhanced retention of both collagen I and collagen III in Cc-ECMs in comparison to NcECMs.

It has been reported that adipocyte lineage cells are activated and intradermal adipocytes repopulate the skin 
to recruit fibroblast to repair cutaneous wound when the skin integrity is lost [53]. Moreover, defects in adipocyte function by genetic or pharmacological intervention seriously impair wound healing and even result in wound recurrence [53]. In this study, we found that Cc-ECMs which exhibited potent healing properties induced a more rapid adipocyte recruitment compared to Nc-ECMs. And the early adipocyte recruitment is associated with better wound healing outcomes. Recently, it has been revealed that adipocytes are capable of transdifferentiating into myofibroblasts in response to TGF- $\beta 1[54,55]$, which play key roles in wound repair through ECM deposition and wound contraction [56]. Therefore, it seemed that the TGF- $\beta 1$ trapped in the Cc-ECMs was responsible for their enhanced wound healing abilities. However, the underlying mechanisms of rapid adipocyte recruitment induced by Cc-ECMs are largely unknown.

Both VEGF and bFGF are well-documented growth factors to promote wound repair by promoting keratinocytes proliferation and migration as well as enhancing angiogenesis $[17,35,57,58]$. In this study, we found that $\mathrm{CoCl}_{2}$ conditioning remarkably upregulated VEGF and bFGF, and their abundance in Cc-ECMs was higher than that in Nc-ECMs, which contributed to the improved wound healing efficacy of Cc-ECMs.

\section{Conclusion}

In this study, we showed that $\mathrm{CoCl}_{2}$ conditioning activated HIF- $1 \alpha$ and significantly increased the expression of both collagens and growth factors in MSC sheets and hence resulted in enriched ECMs with potent in vivo wound healing properties. Although future research should be carried out to optimize decellularization process to retain more growth factors and collagens in the enriched ECMs, it is hoped that the bench-to-bedside translation of the present work will lead to a readily available MSC product that can be clinically used to manage skin injuries.

\section{Conflicts of Interest}

The authors declared no potential conflicts of interest with respect to the research, authorship, and/or publication of this article.

\section{Acknowledgments}

This work was supported by the National Natural Science Foundation of China (nos. 81372077 and 81471877) and the Science and Technology Commission of Shaanxi Province (no. 2014 K11-01-01-24).

\section{References}

[1] S. A. Eming, P. Martin, and M. Tomic-Canic, "Wound repair and regeneration: mechanisms, signaling, and translation," Science Translational Medicine, vol. 6, no. 265, Article ID 265sr6, 2014.

[2] M. Takeo, W. Lee, and M. Ito, "Wound healing and skin regeneration," Cold Spring Harbor Perspectives in Medicine, vol. 5, no. $1,2015$.
[3] B. K. Sun, Z. Siprashvili, and P. A. Khavari, "Advances in skin grafting and treatment of cutaneous wounds," Science, vol. 346, no. 6212, pp. 941-945, 2014.

[4] D. A. Banyard, J. M. Bourgeois, A. D. Widgerow, and G. R. D. Evans, "Regenerative Biomaterials: A Review," Plastic and Reconstructive Surgery, vol. 135, no. 6, pp. 1740-1748, 2015.

[5] A. M. Eweida and M. K. Marei, "Naturally Occurring Extracellular Matrix Scaffolds for Dermal Regeneration: Do They Really Need Cells?” BioMed Research International, vol. 2015, Article ID 839694, 2015.

[6] R. S. Kirsner, G. Bohn, V. R. Driver et al., "Human acellular dermal wound matrix: evidence and experience," International Wound Journal, vol. 12, no. 6, pp. 646-654, 2015.

[7] R. V. Shevchenko, S. L. James, and S. E. James, "A review of tissue-engineered skin bioconstructs available for skin reconstruction," Journal of the Royal Society Interface, vol. 7, no. 43, pp. 229-258, 2010.

[8] P. S. Briquez, J. A. Hubbell, and M. M. Martino, "Extracellular matrix-inspired growth factor delivery systems for skin wound healing," Advances in Wound Care, vol. 4, no. 8, pp. 479-489, 2015.

[9] J. Yang, M. Yamato, C. Kohno et al., "Cell sheet engineering: Recreating tissues without biodegradable scaffolds," Biomaterials, vol. 26, no. 33, pp. 6415-6422, 2005.

[10] J. Yang, M. Yamato, T. Shimizu et al., "Reconstruction of functional tissues with cell sheet engineering," Biomaterials, vol. 28, no. 34, pp. 5033-5043, 2007.

[11] Y.-C. Lin, T. Grahovac, S. J. Oh, M. Ieraci, J. P. Rubin, and K. G. Marra, "Evaluation of a multi-layer adipose-derived stem cell sheet in a full-thickness wound healing model," Acta Biomaterialia, vol. 9, no. 2, pp. 5243-5250, 2013.

[12] M. T. Cerqueira, R. P. Pirraco, T. C. Santos et al., "Human adipose stem cells cell sheet constructs impact epidermal morphogenesis in full-thickness excisional wounds," Biomacromolecules, vol. 14, no. 11, pp. 3997-4008, 2013.

[13] M. M. McLaughlin and K. G. Marra, "The use of adiposederived stem cells as sheets for wound healing," Organogenesis, vol. 9, no. 2, pp. 79-81, 2013.

[14] Y.-R. Kuo, C.-T. Wang, J.-T. Cheng, G.-S. Kao, Y.-C. Chiang, and C.-J. Wang, "Adipose-derived stem cells accelerate diabetic wound healing through the induction of autocrine and paracrine effects," Cell Transplantation, vol. 25, no. 1, pp. 71-81, 2016.

[15] S. H. Lee, S. Y. Jin, J. S. Song, K. K. Seo, and K. H. Cho, "Paracrine effects of adipose-derived stem cells on keratinocytes and dermal fibroblasts," Annals of Dermatology, vol. 24, no. 2, pp. 136-143, 2012.

[16] M. Pakyari, A. Farrokhi, M. K. Maharlooei et al., "Critical role of transforming growth factor beta in different phases of wound healing," Advances in Wound Care, vol. 2, no. 5, pp. 215-224, 2013.

[17] S. Barrientos, H. Brem, O. Stojadinovic, and M. Tomic-Canic, "Clinical application of growth factors and cytokines in wound healing," Wound Repair and Regeneration, vol. 22, no. 5, pp. 569578, 2014.

[18] R. J. Ruthenborg, J.-J. Ban, A. Wazir, N. Takeda, and J.-W. Kim, "Regulation of wound healing and fibrosis by hypoxia and hypoxia-inducible factor-1," Molecules and Cells, vol. 37, no. 9, pp. 637-643, 2014.

[19] E. Andrikopoulou, X. Zhang, R. Sebastian et al., "Current insights into the role of HIF-1 in cutaneous wound healing," Current Molecular Medicine, vol. 11, no. 3, pp. 218-235, 2011. 
[20] A. A. Tandara and T. A. Mustoe, "Oxygen in wound healingmore than a nutrient," World Journal of Surgery, vol. 28, no. 3, pp. 294-300, 2004.

[21] W. X. Hong, M. S. Hu, M. Esquivel et al., "The Role of hypoxiainducible factor in wound healing," Advances in Wound Care, vol. 3, no. 5, pp. 390-399, 2014.

[22] D. Wu and P. Yotnda, "Induction and testing of hypoxia in cell culture," Journal of Visualized Experiments : JoVE, no. 54, article e2899, 2011.

[23] W. Zhou, C. Han, Y. Song et al., "The performance of bone marrow mesenchymal stem cell - Implant complexes prepared by cell sheet engineering techniques," Biomaterials, vol. 31, no. 12, pp. 3212-3221, 2010.

[24] M. C. Prewitz, A. Stißel, J. Friedrichs et al., "Extracellular matrix deposition of bone marrow stroma enhanced by macromolecular crowding," Biomaterials, vol. 73, pp. 60-69, 2015.

[25] X. Wang, J. Ge, E. E. Tredget, and Y. Wu, “The mouse excisional wound splinting model, including applications for stem cell transplantation," Nature Protocols, vol. 8, no. 2, pp. 302-309, 2013.

[26] E. Pacary, H. Legros, S. Valable et al., "Synergistic effects of $\mathrm{CoCl}_{2}$ and ROCK inhibition on mesenchymal stem cell differentiation into neuron-like cells," Journal of Cell Science, vol. 119, no. 13, pp. 2667-2678, 2006.

[27] S. Lord-Dufour, I. B. Copland, L.-C. Levros Jr. et al., "Evidence for transcriptional regulation of the glucose-6-phosphate transporter by HIF-1 $\alpha$ : Targeting G6PT with mumbaistatin analogs in hypoxic mesenchymal stromal cells," Stem Cells, vol. 27, no. 3, pp. 489-497, 2009.

[28] F. Guan, L. Schaffer, K. Handa, and S.-I. Hakomori, "Functional role of gangliotetraosylceramide in epithelial-to-mesenchymal transition process induced by hypoxia and by TGF- $\beta$," FASEB Journal, vol. 24, no. 12, pp. 4889-4903, 2010.

[29] T. Kamiya, H. Hara, N. Inagaki, and T. Adachi, "The effect of hypoxia mimetic cobalt chloride on the expression of EC-SOD in 3T3-L1 adipocytes," Redox Report, vol. 15, no. 3, pp. 131-137, 2010.

[30] C. Befani, I. Mylonis, I.-M. Gkotinakou et al., "Cobalt stimulates HIF-1-dependent but inhibits HIF-2-dependent gene expression in liver cancer cells," The International Journal of Biochemistry and Cell Biology, vol. 45, no. 11, pp. 2359-2368, 2013.

[31] S. Chattopadhyay and R. T. Raines, "Review collagen-based biomaterials for wound healing," Biopolymers, vol. 101, no. 8, pp. 821-833, 2014.

[32] B. J. Larson, M. T. Longaker, and H. P. Lorenz, "Scarless fetal wound healing: a basic science review," Plastic and Reconstructive Surgery, vol. 126, no. 4, pp. 1172-1180, 2010.

[33] K. W. Finnson, S. McLean, G. M. Di Guglielmo, and A. Philip, "Dynamics of transforming growth factor beta signaling in wound healing and scarring," Advances in Wound Care, vol. 2, no. 5, pp. 195-214, 2013.

[34] S. Akita, K. Akino, and A. Hirano, "Basic fibroblast growth factor in scarless wound healing," Advances in Wound Care, vol. 2, no. 2, pp. 44-49, 2013.

[35] K. E. Johnson and T. A. Wilgus, "Vascular endothelial growth factor and angiogenesis in the regulation of cutaneous wound repair," Advances in Wound Care, vol. 3, no. 10, pp. 647-661, 2014.

[36] Y. Kato, T. Iwata, S. Morikawa, M. Yamato, T. Okano, and Y. Uchigata, "Allogeneic transplantation of an adipose-derived stem cell sheet combined with artificial skin accelerates wound healing in a rat wound model of type 2 diabetes and obesity," Diabetes, vol. 64, no. 8, pp. 2723-2734, 2015.

[37] M. Li, Y. Zhao, H. Hao, W. Han, and X. Fu, "Mesenchymal stem cell-based therapy for nonhealing wounds: Today and tomorrow," Wound Repair and Regeneration, vol. 23, no. 4, pp. 465-482, 2015.

[38] G. T. S. Kirby, S. J. Mills, A. J. Cowin, and L. E. Smith, "Stem cells for cutaneous wound healing," BioMed Research International, vol. 2015, Article ID 285869, 2015.

[39] C. Tong, H. Hao, L. Xia et al., "Hypoxia pretreatment of bone marrow-derived mesenchymal stem cells seeded in a collagen-chitosan sponge scaffold promotes skin wound healing in diabetic rats with hindlimb ischemia," Wound Repair and Regeneration, vol. 24, no. 1, pp. 45-56, 2016.

[40] E. K. Jun, Q. Zhang, and B. S. Yoon, "Hypoxic conditioned medium from human amniotic fluid-derived mesenchymal stem cells accelerates skin wound healing through TGF$\beta /$ SMAD2 and PI3K/AKT pathways," International Journal of Molecular Sciences, vol. 15, no. 1, pp. 605-628, 2014.

[41] L. Chen, Y. Xu, J. Zhao et al., "Conditioned medium from hypoxic bone marrow-derived mesenchymal stem cells enhances wound healing in mice," PLoS ONE, vol. 9, article e96161, no. 4, 2014.

[42] L. Du, R. Lv, X. Yang, S. Cheng, T. Ma, and J. Xu, "Hypoxic conditioned medium of placenta-derived mesenchymal stem cells protects against scar formation," Life Sciences, vol. 149, pp. 51-57, 2016.

[43] P. M. Crapo, T. W. Gilbert, and S. F. Badylak, "An overview of tissue and whole organ decellularization processes," Biomaterials, vol. 32, no. 12, pp. 3233-3243, 2011.

[44] A. Srivastava, E. Z. DeSagun, L. J. Jennings et al., "Use of porcine acellular dermal matrix as a dermal substitute in rats," Annals of Surgery, vol. 233, no. 3, pp. 400-408, 2001.

[45] J.-K. Chai, L.-M. Liang, H.-M. Yang et al., "Preparation of laser micropore porcine acellular dermal matrix for skin graft: an experimental study," Burns, vol. 33, no. 6, pp. 719-725, 2007.

[46] K.-C. Tark, S. Chung, K.-S. Shin, and B.-Y. Park, "Skin flap prefabrication using acellular dermal matrix and cultured keratinocytes in a porcine model," Annals of Plastic Surgery, vol. 44, no. 4, pp. 392-397, 2000.

[47] X. Zhang, Z. Deng, H. Wang et al., "Expansion and delivery of human fibroblasts on micronized acellular dermal matrix for skin regeneration," Biomaterials, vol. 30, no. 14, pp. 2666-2674, 2009.

[48] L. Ge, S. Zheng, and H. Wei, "Comparison of histological structure and biocompatibility between human acellular dermal matrix (ADM) and porcine ADM,' Burns, vol. 35, no. 1, pp. 46$50,2009$.

[49] T. M. MacLeod, P. Sarathchandra, G. Williams, R. Sanders, and C. J. Green, "Evaluation of a porcine origin acellular dermal matrix and small intestinal submucosa as dermal replacements in preventing secondary skin graft contraction," Burns, vol. 30, no. 5, pp. 431-437, 2004.

[50] M. Saito, K. Marumo, K. Fujii, and N. Ishioka, "Single-column high-performance liquid chromatographic-fluorescence detection of immature, mature, and senescent cross-links of collagen," Analytical Biochemistry, vol. 253, no. 1, pp. 26-32, 1997.

[51] E. A. Makris, D. J. Responte, N. K. Paschos, J. C. Hu, and K. A. Athanasiou, "Developing functional musculoskeletal tissues 
through hypoxia and lysyl oxidase-induced collagen crosslinking," Proceedings of the National Academy of Sciences of the United States of America, vol. 111, no. 45, pp. E4832-4841, 2014.

[52] D. M. Gilkes, G. L. Semenza, and D. Wirtz, "Hypoxia and the extracellular matrix: drivers of tumour metastasis," Nature Reviews Cancer, vol. 14, no. 6, pp. 430-439, 2014.

[53] B. A. Schmidt and V. Horsley, "Intradermal adipocytes mediate fibroblast recruitment during skin wound healing," Development (Cambridge), vol. 140, no. 7, pp. 1517-1527, 2013.

[54] J. Hutchenreuther and A. Leask, "A tale of two orgins: do myofibroblasts originate from different sources in wound healing and fibrosis?" Cell and Tissue Research, vol. 365, no. 3, pp. 507-509, 2016.

[55] R. G. Marangoni, B. D. Korman, J. Wei et al., "Myofibroblasts in murine cutaneous fibrosis originate from adiponectin-positive intradermal progenitors," Arthritis \& Rheumatology, vol. 67, no. 4, pp. 1062-1073, 2015.

[56] I. A. Darby, B. Laverdet, F. Bonté, and A. Desmoulière, "Fibroblasts and myofibroblasts in wound healing," Clinical, Cosmetic and Investigational Dermatology, vol. 7, pp. 301-311, 2014.

[57] S. Barrientos, O. Stojadinovic, M. S. Golinko, H. Brem, and M. Tomic-Canic, "Growth factors and cytokines in wound healing," Wound Repair and Regeneration, vol. 16, no. 5, pp. 585-601, 2008.

[58] M. A. Seeger and A. S. Paller, "The Roles of Growth Factors in Keratinocyte Migration," Advances in Wound Care, vol. 4, no. 4, pp. 213-224, 2015. 


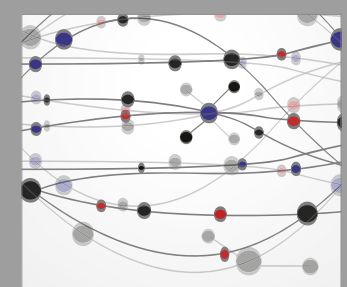

The Scientific World Journal
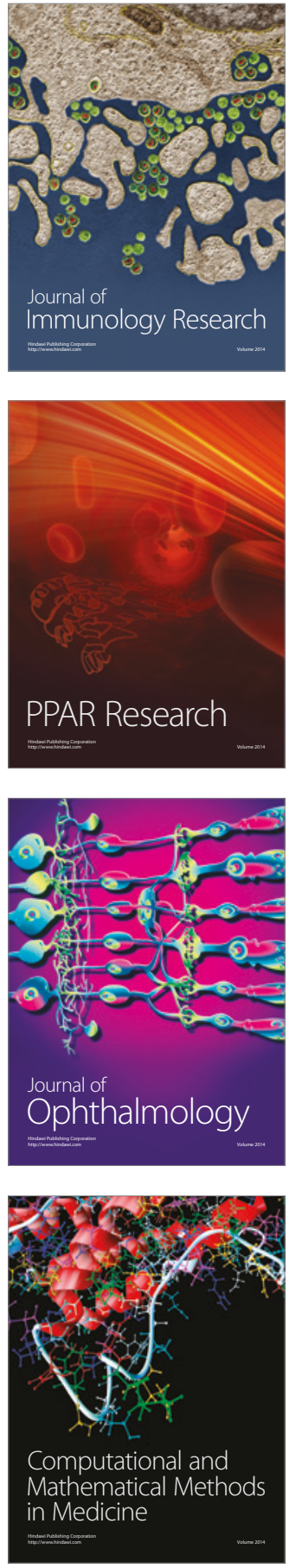

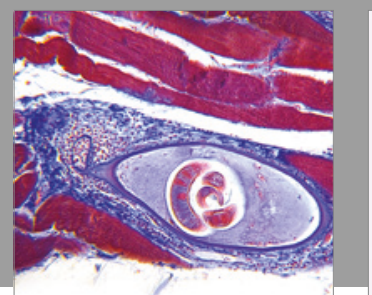

Gastroenterology Research and Practice
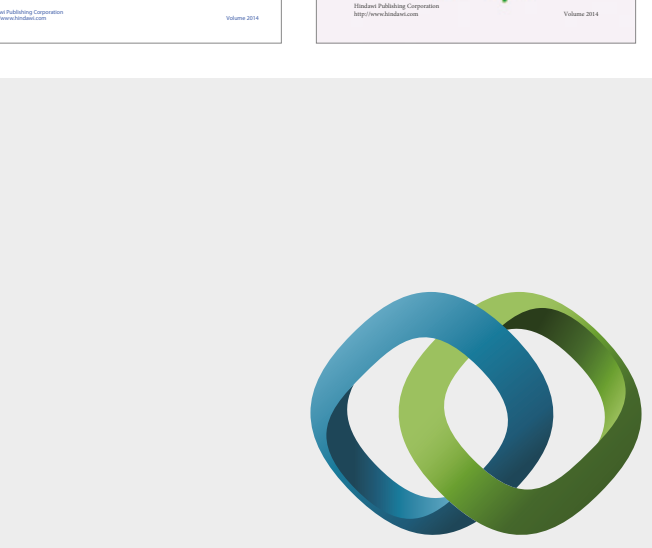

\section{Hindawi}

Submit your manuscripts at

https://www.hindawi.com
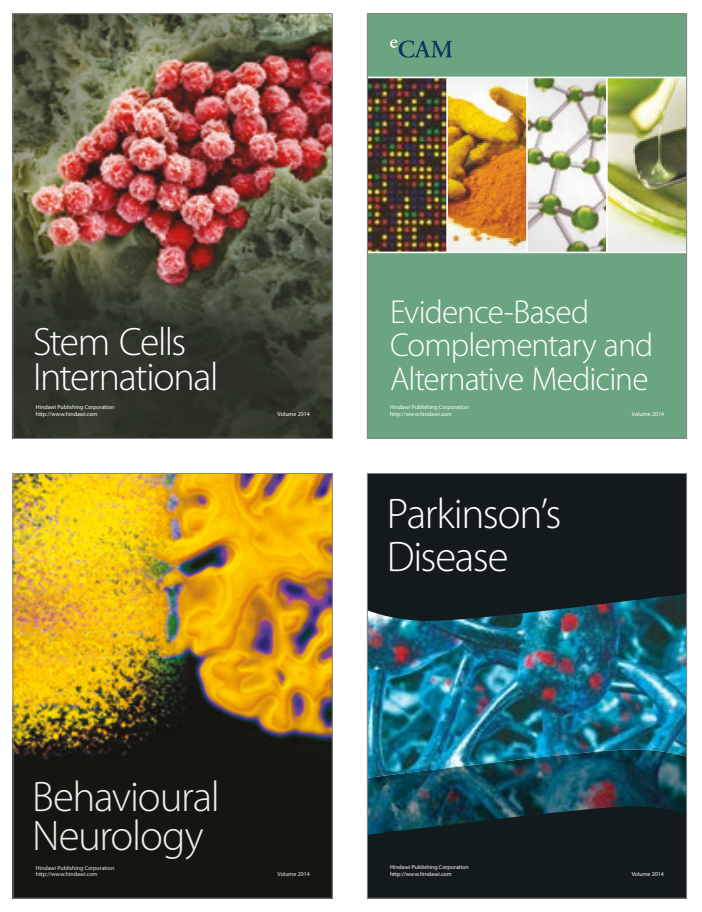
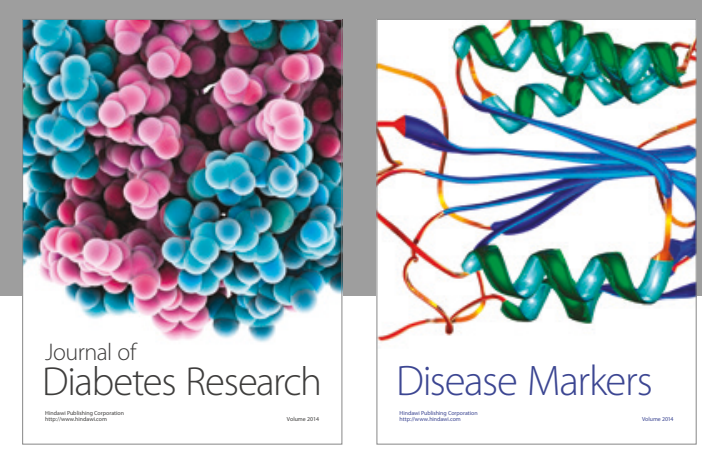

Disease Markers
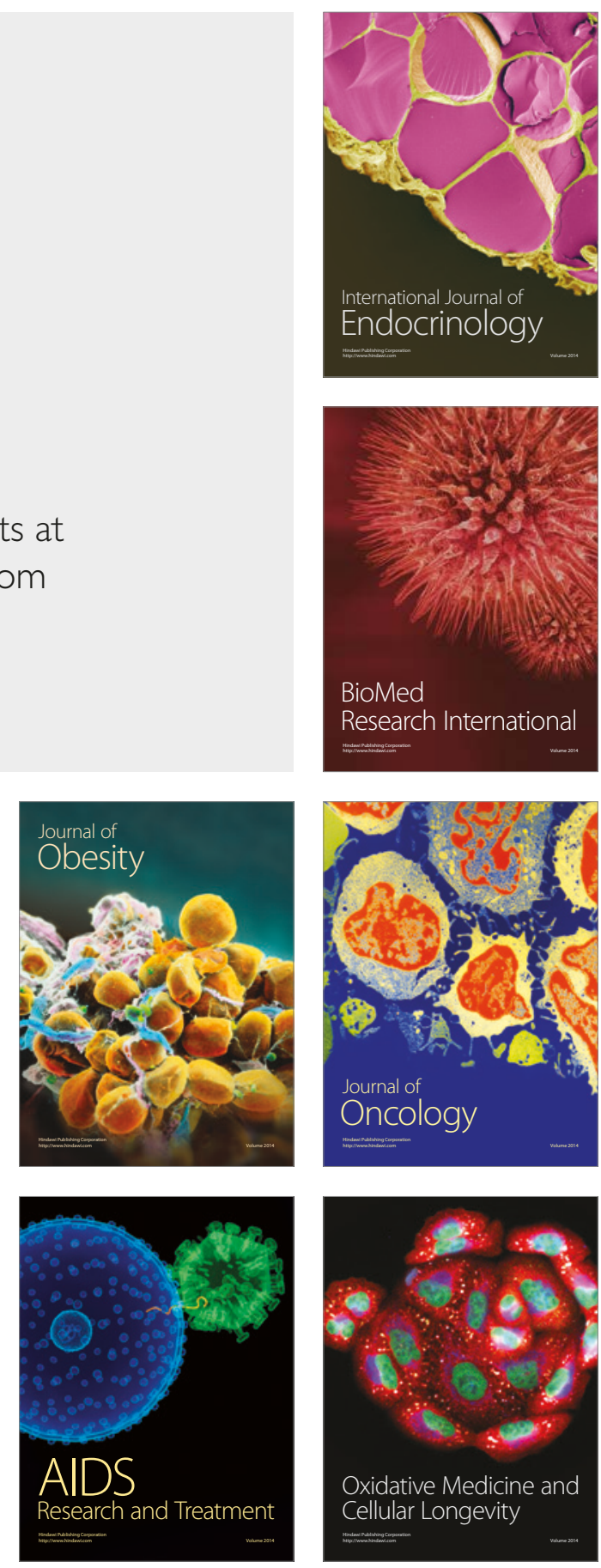